\title{
ALFABETIZAÇÃO CIENTÍFICA, ENSINO POR INVESTIGAÇÃO E ARGUMENTAÇÃO: RELAÇÕES ENTRE CIÊNCIAS DA NATUREZA E ESCOLA
}

\author{
Lúcia Helena Sasseron* \\ Faculdade de Educação da Universidade de São Paulo
}

RESUMO: O objetivo deste trabalho é discutir e buscar relações entre as ideias que circundam a Alfabetização Científica, o Ensino por Investigação e a Argumentação em situações de Ensino de Ciências da natureza. Para tanto, optamos por trazer à tona discussões acerca da escola como um espaço em que culturas são apresentadas, produzidas e negociadas. Ao longo do texto, identificamos elementos que configuram a cultura escolar e a cultura científica. Nossa proposta discute movimentos para a concretização de uma cultura híbrida nas aulas de ciências da natureza: a cultura científica escolar. Finalizamos o texto destacando de que modo a Alfabetização Científica, o Ensino por Investigação e a Argumentação permitem a concretização do estabelecimento da cultura científica escolar.

Palavras-chave: Alfabetização científica. Ensino por investigação. Argumentação.

\section{ALFABETIZACIÓN CIENTÍFICA, ENSEÑANZA POR INVESTIGACIÓN Y ARGUMENTACIÓN: RELACIONES ENTRE LAS CIENCIAS DE LA NATURALEZA Y LA ESCUELA}

RESUMEN: El objetivo de este trabajo es discutir y buscar relaciones entre las ideas que rodean la alfabetización científica, la enseñanza por investigación y la argumentación en situaciones de enseñanza de las ciencias de la naturaleza. Para tanto, se optó por abrir las discusiones acerca de la escuela como un lugar donde se presentan, producen y negocian culturas. A lo largo del texto, se identifican elementos que dan forma a la cultura escolar y a la cultura científica. Nuestra propuesta discute movimientos para la realización de una cultura híbrida en las clases de ciencias de la naturaleza: la cultura científica de la escuela. Finalizamos el texto destacando cómo la Alfabetización Científica, Educación para la Investigación y la Argumentación permiten el establecimiento concreto de la cultura científica de la escuela.

Palabras clave: Alfabetización científica. Enseñanza por investigación. Argumentación.
*Doutora em Educação pela Universidade de São Paulo (USP). Professora Doutora da Faculdade de Educacão da USP e Pesquisadora do LaPÉF (Laboratório de Pesquisa e Ensino de Física) da Faculdade de Educacão da USP. E-mail: sasseron@usp.br 
SCIENTIFIC LITERACY, TEACHING BY RESEARCH AND ARGUMENTATION: RELATIONS BETWEEN NATURAL SCIENCES AND SCHOOL

ABSTRACT: The main goal of this work is to discuss and seek relations between ideas that surround scientific literacy, teaching by research and the argumentation in situations of natural sciences teaching. To this end, we choose to bring up discussions about school as a space where other cultures are presented, produced and negotiated. In this paper, elements that shape school culture and scientific culture are presented. Our proposal discusses moves to the realization of a hybrid culture in natural sciences classes: the school scientific culture. We conclude this work by highlighting how Scientific Literacy, Teaching by Research and Debate allow the concrete establishment of school scientific culture.

Keywords: Scientific Literacy. Inquiry-based teaching. Argumentation. 


\section{INTRODUCุÃO}

O título deste trabalho já evidencia caminhos os quais pretendemos trilhar. Ao longo de anos de trabalhos e estudos, as pesquisas de nosso grupo LaPEF ${ }^{1}$ apontam-nos encontros e relações entre a Alfabetização Científica, o Ensino por Investigação e a Argumentação no contexto de aulas de ciências (CAPECCHI, 2004; LOCATELLI, 2006; CAPECCHI; CARVALHO, 2000; SASSERON, 2008; SASSERON; CARVALHO, 2008, 2011; BARRELOJÚNIOR, 2010; MACHADO, 2012; entre outros).

Em linhas gerais, podemos afirmar que a Alfabetização Científica tem se configurado no objetivo principal do ensino das ciências na perspectiva de contato do estudante com os saberes provenientes de estudos da área e as relações e os condicionantes que afetam a construção de conhecimento científico em uma larga visão histórica e cultural. $\mathrm{O}$ ensino por investigação e a argumentação, por outro lado, cumprem uma função dupla em nossas pesquisas: ao mesmo tempo em que representam modalidades de interação trabalhadas para o desenvolvimento da Alfabetização Científica em sala de aula, constituem-se em formas de estudo dos dados provenientes de nossas pesquisas (CARVALHO, 2013; MACHADO; SASSERON, 2012; FERRAZ; SASSERON, 2012; entre outros). Essa dubiedade, que pode ser encarada como um empecilho a um estudo cuidadoso e criterioso, tem nos possibilitado avanços no entendimento que vemos construído acerca do papel de professores e estudantes no desenvolvimento de um Ensino de Ciências que possa atender às demandas sociais e oficiais em termos de formação de pessoas, sujeitos na sociedade atual.

Nosso objetivo com este trabalho é discutir a escola como um espaço de culturas, destacando a influência da cultura escolar para o desenvolvimento de práticas didáticas. Ao mesmo tempo, discutimos aspectos vinculados à cultura científica. Desse modo, torna-se possível refletir acerca de uma pretensa cultura científica escolar e, junto a isso, identificar como a Alfabetização Científica, o Ensino por Investigação e a Argumentação podem se relacionar e contribuir para o aprendizado das ciências da natureza em sala de aula.

\section{O QUE ENSINAR EM AULAS DE CIÊNCIAS?}

A pergunta acima certamente é considerada em diferentes ocasiões em que se discute a organização, a finalidade e a relevância do Ensino de Ciências para a sociedade.

É bem sabido que a influência das ciências em nossa sociedade não é unidirecional, o que evidencia a importância de que não se reconheça a ciência e a sociedade apartadas, uma à mercê da outra.

Para além disso, não se pode, ao mesmo tempo, ignorar os avanços e as transformações que uma e outra sofrem a todo instante. São, portanto, ciência e sociedade, transformadas e transformadoras. 
À parte as questões filosóficas sobre disciplinas e currículos, o ensino das ciências da natureza ganha aval e importância na consideração das ciências não apenas como um corpo de conhecimentos organizado e legitimado pela sociedade humana, mas, sobretudo, pelo transbordamento das questões que envolvem as ciências para além da esfera de seu contexto de produção.

Ensinar ciências, sob essa perspectiva, implica dar atenção a seus produtos e a seus processos. Implica oportunizar o contato com um corpo de conhecimentos que integra uma maneira de construir entendimento sobre o mundo, os fenômenos naturais e os impactos destes em nossas vidas. Implica, portanto, não apenas reconhecer os termos e os conceitos canônicos das ciências de modo a poder aplicá-los em situações atuais, pois o componente da obsolescência integra a própria ciência e o modo como dela e de seus conhecimentos nos apropriamos.

Conhecer as ciências tem, portanto, um alto grau de comprometimento com a percepção de que o mundo está em constante modificação, sendo importante e necessária a permanente busca por construir entendimento acerca de novas formas de conceber os fenômenos naturais e os impactos que estes têm sobre nossa vida.

\section{A SALA DE AULA DE CIÊNCIAS}

Como espaço tradicionalmente relacionado ao ensino, as salas de aula permitem que o trabalho e as relações entre alunos e professor ocorram. Considerando que materiais contribuem para a concretização de atividades e para a mediação intencionada na discussão sobre conhecimentos, a organização do espaço escolar exerce influência nas relações estabelecidas, ancorando comportamentos e auxiliando no desenvolvimento de práticas (VINÃOFRAGO; ESCOLANO, 1998) e colocando em prática o trabalho com as disciplinas reconhecidas nos currículos das escolas.

Para além das salas de aula, laboratórios costumam estar vinculados às práticas das aulas de ciências. Infelizmente, a realidade que hoje encontramos na grande maioria das escolas brasileiras deixa claro que esse espaço tem recebido cada vez menos atenção, implicando não apenas o escasso suporte para que seja utilizado, devido à falta de manutenção e de reposição de itens centrais, como também a falta de condições para planejamento e organização hábeis, acarretando em casos frequentes de adaptação desse espaço para outras atividades.

A importância do laboratório para as práticas em aulas de ciências da natureza não está dada a priori, mas explicita-se a partir da construção do currículo e da didática de cada escola e de cada professor. No mesmo sentido, é possível dizer que o laboratório de informática, a biblioteca ou o pátio são igualmente espaços que podem ser aproveitados para a concretização de práticas relacionadas a temas das ciências da natureza. O que torna esses espaços adequados ou apropriados está mais vinculado aos objetivos do ensino do que exatamente à sua constituição como espaço físico. 
Sob essa perspectiva, decorre que a sala de aula de ciências da natureza em muito pouco ou quase nada difere de uma sala de aula de outra disciplina qualquer. Esse fato, em certos aspectos, está muito menos ligado a questões de ordem espacial e física e mais vinculado a questões pedagógicas e gerenciais da escola, ou mesmo a escolhas curriculares traçadas no plano administrativo. Em outras palavras, na grande maioria dos casos, as salas de aula escolares não representam espaço físico com preocupação voltada ao desenvolvimento de práticas próprias de uma área de conhecimento, mas sim ao desenvolvimento de práticas didáticas e pedagógicas que podem não corresponder, de modo adequado, ao que se espera do ensino de um campo de conhecimento.

O que queremos destacar é que dimensões históricas e sociais da escola podem influenciar a maneira como os conteúdos são trabalhadose, eventualmente, influenciar o estabelecimento da própria cultura escolar, podem, inclusive, acarretar na abordagem de disciplinas escolares que pouco ou quase nada se relacionam com a área de conhecimento que representam.

\section{A ESCOLA COMO ESPAÇO DE ENCONTRO DE CULTURAS}

É atribuída à escola, entre outras, a função de oferecer cultura para aqueles que se encontram em seu espaço. Via de regra, espera-se que a cultura erudita seja apresentada aos estudantes. Mas não podemos deixar de lado que a escola, como espaço físico que congrega pessoas de diferentes experiências, realidades e perspectivas sociais e culturais distintas, também congrega diferentes culturas, além de, ela mesma, possuir características que definem sua própria cultura.

Definir cultura não é algo simples. Existe vasta produção sobre o tema apontando direcionamentos, por exemplo, de ordem antropológica, sociológica ou filosófica para a compreensão de cultura. Para esse recorte, limitamo-nos a estudar autores que tratam a cultura como composta por crenças, ideologias, organização social e tecnologias (EAGLETON, 2005; ELIOT, 1988; WHITE; DILLINGHAM, 2009; entre outros). Em linhas gerais, podemos sintetizar a ideia de cultura como sendo composta por normas e práticas: normas que regem o que se faz e práticas da forma como essas ações são desempenhadas. E, ainda conforme Eagleton (2005), cultura pode ser vista como uma relação dialética que tem, por um lado, regulação e, por outro, crescimento espontâneo.

Usando essa linha de pensamento, cultura não pode ser entendida senão por meio de relações. E, com base nessas ideias iniciais sobre cultura, demandando considerá-la de modo contextualizado, entendemos que seja importante colocar a própria ideia de cultura em relação a algo.

De modo mais direto às relações estabelecidas na escola, estar nesta instituição já é participar de uma cultura. Concepções e juízos sobre o que seja a escola antes mesmo de conhecê-la encontram-se com experiências e conhecimentos 
acerca da realidade e das ações que perpassam estar na escola e participar de suas atividades. A cultura escolar, portanto, carrega elementos da relação entre estar na escola, ser parte da escola e fazer a escola.

Dominique Julia propõe a cultura escolar "[...] descrita como um conjunto de normas que definem conhecimentos a ensinar e condutas a inculcar, e um conjunto de práticas que permitem a transmissão desses conhecimentos e a incorporação desses comportamentos" (JULIA, 2001, p. 9).

$\mathrm{Na}$ escola, normas são definidas, por exemplo, por diretrizes curriculares, pelo projeto político pedagógico da escola, pelo regimento escolar, pelo contato do professor com suas turmas, podendo ser legitimadas por essas mesmas pessoas ou pelas diretrizes. Práticas escolares podem ser encontradas, por exemplo, nas atividades de sala de aula realizadas por professor e alunos, conversas entre professores sobre planejamento e atividades em momentos informais, como intervalos, brincadeiras e jogos escolares.

Considerando esse ponto de vista, assim como a própria definição de cultura mostra-se complexa e ampla (CERTEAU, 1994), a cultura escolar pode ser múltipla e, certamente, está ancorada em contexto e relações que se estabelecem pelo convívio e pelas experiências vivenciadas em âmbito escolar.

É claro, por exemplo, que na escola cabe aos alunos o papel de aprendizes e ao professor, o dever de instruir. Técnicas, métodos, atividades, práticas são todos realizados na expectativa de que a instrução possa gerar aprendizagem. Ao mesmo tempo, técnicas, métodos, atividades e práticas buscam avaliar os resultados obtidos pela interação realizada.

Seria esperado que essas ações estivessem ancoradas em aspectos próprios de cada corpo disciplinar, respeitando e explorando não apenas questões conceituais, mas também dimensões de uma área de conhecimento. Contudo, não é incomum encontrar escolas em que espaço físico e metodologias não se diferem na abordagem de distintas disciplinas. Há, portanto, um modo de estar na escola e de apresentar conhecimentos escolares sobre as disciplinas que não se relaciona com a cultura própria da área de conhecimento.

Cabe, então, uma pergunta central: a escola ensina disciplinas ou ensina sobre modos de perceber o mundo? Infelizmente, tendemos a crer que, como resposta, encontramos mais frequentemente a primeira opção: a escola ensina modos de se relacionar com conteúdos que estão intimamente vinculados a práticas estabelecidas no espaço escolar.

O impasse mais uma vez está colocado: o que seria esperado que a escola ensinasse em aulas de ciências da natureza?

Para essa defesa, devemos recorrer ao que entendemos da ciência como uma cultura. 


\section{CIÊNCIA COMO CULTURA}

É claramente possível estabelecer a ciência como uma cultura trazendo de volta as perspectivas anteriormente tratadas; e, assim como uma definição de cultura pode colocar em destaque aportes sociológicos, antropológicos e históricos, definir ciência requer considerar esses múltiplos olhares.

No livro $A$ vida de laboratório: a produção dos fatos científicos, Bruno Latour e Steve Woolgar (1997) relatam a experiência de Latour de conviver cotidianamente, ao longo de dois anos, com uma equipe de técnicos e cientistas que trabalhavam em um laboratório de neuroendocrinologia. Sua experiência permitiu contato com etapas realizadas pelos pesquisadores desde experimentos empíricos até a publicação de artigos científicos. Dessa experiência antropológica, os autores analisam os fatos e propõem que a atividade científica não se distingue de nenhuma outra atividade social; pontuam, ainda, a necessidade de os cientistas apresentarem suas considerações de modo persuasivo, com o objetivo de garantir a aceitação destas.

Latour e Woolgar destacam as interações entre os cientistas, as interações destes com os materiais presentes, as burocracias internas existentes no trabalho no laboratório e os esforços para propor fatos e artefatos científicos (fatos seriam aquelas proposições legitimadas e artefatos, aquelas não tão bem-sucedidas). É possível, já por essas poucas ideias, perceber que o trabalho científico não é algo feito isoladamente, ato advindo de cabeças de pessoas iluminadas. Proposições são construídas como forma de apoiar e de sintetizar fatos e evidências em análise, assim como fatos e evidências podem ser construídos para sustentar proposições.

Em uma perspectiva histórica, é possível identificar que as ciências da natureza, assim como qualquer empreendimento humano, têm seu avanço associado a questões de ordens social, cultural e histórica. Essa influência mútua e permanente pode nos apresentar modos diferentes para a compreensão do que venham a ser essas ciências, pois relata, além da existência de interações entre pessoas, as relações que são tecidas entre novas evidências, observações, suposições e novos experimentos e os conhecimentos já legitimados.

A partir dessas ideias acerca do trabalho científico, podemos conceber a cultura científica como o conjunto de ações e de comportamentos envolvidos na atividade de investigação e divulgação de um novo conhecimento sobre o mundo natural.

Em linhas gerais, é possível afirmar que lógica e objetividade costumam ser as bases que fundamentam a construção e a proposição dos conhecimentos científicos. A construção e o teste de hipóteses, a busca por evidências e justificativas também perpassam as ações do fazer científico, e a divulgação das ideias pauta-se, muitas vezes, na tentativa de convencimento do que se propõe. Ritos e crenças também acompanham essa cultura e definem, em certos contextos, o grau de aceitabilidade das proposições.

Nas ciências da natureza, as normas podem estar ligadas, por exemplo, à divulgação dos resultados em periódicos, eventos e reuniões, ao estabelecimento 
de acordos éticos para coleta e análise de informações. As práticas estão ligadas, por exemplo, aos métodos utilizados por um pesquisador para a análise de dados, à construção de hipóteses e à busca de evidências que a corroborem ou não, ao esforço por tornar clara sua proposição.

Reconhecendo as ideias sobre cultura escolar e sobre cultura científica, entendemos que a escola deve perseguir a meta de concretização de conhecimentos e atitudes relacionados às ciências da natureza não apenas como uma disciplina escolar, mas como área de conhecimento da humanidade. O que seria esse objetivo educacional?

\section{ALGUMAS IDEIAS SOBRE ALFABETIZAC̣ÃO CIENTÍFICA}

Pesquisas sobre Alfabetização Científica vêm sendo realizadas em todo o mundo (BYBEE; DEBOER, 1994; FOUREZ, 1994; HURD, 1998; entre outros). $\mathrm{E}$, no Brasil, ainda que pairem discussões acerca de qual termo adotar - alfabetização, letramento ou enculturação científica -, os preceitos e os objetivos para o Ensino de Ciências registram a clara intenção de formação capaz de prover condições para que temas e situações envolvendo as ciências sejam analisados à luz dos conhecimentos científicos, sejam estes conceitos ou aspectos do próprio fazer científico. Pode-se afirmar que a Alfabetização Científica, ao fim, revela-se como a capacidade construída para a análise e a avaliação de situações que permitam ou culminem com a tomada de decisões e o posicionamento.

Sob essa perspectiva, a Alfabetização Científica é vista como processo e, por isso, como contínua. Ela não se encerra no tempo e não se encerra em si mesma: assim como a própria ciência, a Alfabetização Científica deve estar sempre em construção, englobando novos conhecimentos pela análise e em decorrência de novas situações; de mesmo modo, são essas situações e esses novos conhecimentos que impactam os processos de construção de entendimento e de tomada de decisões e posicionamentos e que evidenciam as relações entre as ciências, a sociedade e as distintas áreas de conhecimento, ampliando os âmbitos e as perspectivas associadas à Alfabetização Científica.

Em trabalhos anteriores, temos proposto maneiras de considerar a Alfabetização Científica no planejamento de aulas e na avaliação da implementação destas (SASSERON; CARVALHO, 2008, 2011). Os Eixos Estruturantes da Alfabetização Científica surgiram da análise de referenciais da área de Ensino de Ciências que apresentavam ideias e habilidades a serem desenvolvidas com o intuito de que a Alfabetização Científica pudesse estar em processo. Eles marcam grandes linhas orientadoras para o trabalho em sala de aula e transitam entre pontos canônicos do currículo de ciências e elementos que marcam a apropriação desses conhecimentos para ações em esferas extraescolares. Ainda que os três eixos estruturantes possam não se fazer presentes em todas as aulas, é necessário que eles sejam equitativamente considerados ao longo do desenvolvimento de um 
tema. Os três eixos são: (a) a compreensão básica de termos e conceitos científicos, retratando a importância de que os conteúdos curriculares próprios das ciências sejam debatidos na perspectiva de possibilitar o entendimento conceitual; (b) a compreensão da natureza da ciência e dos fatores que influenciam sua prática, deflagrando a importância de que o fazer científico também ocupa espaço nas aulas de mais variados modos, desde as próprias estratégias didáticas adotadas, privilegiando a investigação em aula, passando pela apresentação e pela discussão de episódios da história das ciências que ilustrem as diferentes influências presentes no momento de proposição de um novo conhecimento; e (c) o entendimento das relações entre ciência, tecnologia, sociedade e ambiente, permitindo uma visão mais completa e atualizada da ciência, vislumbrando relações que impactam a produção de conhecimento e são por ela impactadas, desvelando, uma vez mais, a complexidade existente nas relações que envolvem o homem e a natureza.

Com o objetivo de avaliar a implementação de propostas visando à Alfabetização Científica levadas para a sala de aula, propusemos também os indicadores de Alfabetização Científica. Trata-se de habilidades vinculadas à construção de entendimento sobre temas das ciências que podem estar em processo em sala de aula e evidenciam o papel ativo dos estudantes na busca pelo entendimento dos temas curriculares das ciências. Esses indicadores referem-se: (a) ao trabalho com as informações e com os dados disponíveis, seja por meio da organização, da seriação e da classificação de informações; (b) ao levantamento e ao teste de hipóteses construídas que são realizados pelos estudantes; (c) ao estabelecimento de explicações sobre fenômenos em estudo, buscando justificativas para torná-las mais robustas e estabelecendo previsões delas advindas; e (d) ao uso de raciocínio lógico e raciocínio proporcional durante a investigação e a comunicação de ideias em situações de ensino e aprendizagem. Não devem ser tomados como um método que se espera implementar ou atingir e, portanto, não devem ser avaliados na perspectiva de ocorrência cronológica, pois representam, de modo mais específico, o envolvimento evidenciado ao longo de processos de discussão e resolução de problemas ligados às ciências e trabalhados em situações de ensino.

Portanto, temos alguns apontamentos que oferecem direcionamento para o planejamento e a avaliação de situações em que a Alfabetização Científica esteja em pauta. Masuma pergunta central ainda não foi feita: como desenvolver práticas em sala de aula que permitam aos alunos o desenvolvimentode atitudes críticas, analíticas e propositivas frente a temas científicos que afligem a sociedade?

\section{O ENSINO POR INVESTIGAC̣ÃO COMO ABORDAGEM DIDÁTICA}

O ensino por investigação também tem sido interesse de estudo de diversas pesquisas. Buscando colocar em evidência como o ensino por investigação vem sendo tratado e discutido ao longo dos anos, Grandy e Duschl (2007) destacam que a agenda do ensino por investigação ganha lugar nos currículos pelos 
objetivos de levar os estudantes a realizarem investigação e de desenvolver entre os estudantes um entendimento sobre o que seja a investigação científica. Os autores ainda colocam em destaque que o próprio entendimento acerca do fazer científico vem sendo modificado, e, portanto, surge a necessidade também de se alterar a própria ideia de investigação tal qual é levada para a sala de aula. Desse modo, lembram que, assim como a própria construção de conhecimento em ciências, a investigação em sala de aula deve oferecer condições para que os estudantes resolvam problemas e busquem relações causais entre variáveis para explicar o fenômeno em observação, por meio do uso de raciocínios do tipo hipotético-dedutivo, mas deve ir além: deve possibilitar a mudança conceitual, o desenvolvimento de ideias que possam culminar em leis e teorias, bem como a construção de modelos.

Considerando essas ideias, entendemos que o ensino por investigação extravasa o âmbito de uma metodologia de ensino apropriada apenas a certos conteúdos e temas, podendo ser colocada em prática nas mais distintas aulas, sob as mais diversas formas e para os diferentes conteúdos. Denota a intenção do professor em possibilitar o papel ativo de seu aluno na construção de entendimento sobre os conhecimentos científicos. Por esse motivo, caracteriza-se por ser uma forma de trabalho que o professor utiliza na intenção de fazer com que a turma se engaje com as discussões e, ao mesmo tempo em que travam contato com fenômenos naturais, pela busca de resolução de um problema, exercitam práticas e raciocínios de comparação, análise e avaliação bastante utilizadas na prática científica.

Tomando-o como associado ao trabalho do professor e não apenas a uma estratégia específica, o ensino por investigação configura-se como uma abordagem didática, podendo, portanto, estar vinculado a qualquer recurso de ensino desde que o processo de investigação seja colocado em prática e realizado pelos alunos a partir e por meio das orientações do professor.

Como abordagem didática, o ensino por investigação demanda que o professor coloque em prática habilidades que ajudem os estudantes a resolver problemas a eles apresentados, devendo interagir com seus colegas, com os materiais à disposição, com os conhecimentos já sistematizados e existentes. Ao mesmo tempo, o ensino por investigação exige que o professor valorize pequenas ações do trabalho e compreenda a importância de colocá-las em destaque como, por exemplo, os pequenos erros e/ou imprecisões manifestados pelos estudantes, as hipóteses originadas em conhecimentos anteriores e na experiência de sua turma, as relações em desenvolvimento. É um trabalho em parceria entre professor e estudantes. Uma construção de entendimento sobre o que seja a ciência e sobre os conceitos, modelos e teorias que a compõem; nesse sentido, é uma construção de uma nova forma de vislumbrar os fenômenos naturais e o modo como estamos a eles conectados e submetidos, sendo a linguagem uma forma de relação com esses conhecimentos e também um aspecto a ser aprendido.

Mais recentemente, em nosso grupo de pesquisa, começamos a trabalhar para o desenvolvimento de Sequências de Ensino Investigativas - SEI (CARVALHO, 2011; CARVALHO; SASSERON, 2012). O objetivo central na proposição de 
SEI é permitir que investigações sejam realizadas em aulas que, a princípio, são reconhecidas como distintas e, por vezes, não associadas à investigação. Ao trabalhar na implementação de SEI, o professor precisa garantir que tanto a atividade experimental quanto a leitura de textos, por exemplo, sejam igualmente investigativas, ou seja, tenham por trás um problema claro que precise ser resolvido.

Em breves palavras, uma sequência de ensino investigativa é o encadeamento de atividades e aulas em que um tema é colocado em investigação e as relações entre esse tema, conceitos, práticas e relações com outras esferas sociais e de conhecimento possam ser trabalhados.

Essa concepção reforça a ideia do ensino por investigação como abordagem didática, pois denota o papel do professor de propositor de problemas, orientador de análises e fomentador de discussões, independente de qual seja a atividade didática proposta.

Delimitado esse papel do professor, cabe perguntar: e o aluno? Qual o papel dos estudantes no ensino por investigação? Qual o papel do ensino por investigação na formação dos alunos?

\section{ARGUMENTAÇÃO NO ENSINO DE CIÊNCIAS}

Fundamentada na dialética, uma das possíveis formas de definir a argumentação sustenta-se na ideia da defesa de pontos de vista ou de alternativas de ação. Leitão (2011), considerando essa perspectiva, entende que a argumentação "não é somente uma atividade discursiva da qual os indivíduos eventualmente participam, mas, sobretudo, uma forma básica de pensamento que permeia a vida humana" (p. 14).

Levar em contaa argumentação como forma básica de pensamento implica a possibilidade de que ela seja tomada para avaliar processos de construção de entendimento, pois a explicitação da argumentação, em seu ato discursivo, seja pela oralidade seja por registros gráficos, permitiria evidenciar as perspectivas de construção de entendimento de processos, ideias, conceitos e posições. Sob essa perspectiva, ainda que a argumentação explicite pontos de vista divergentes, isso implica e resulta em processos de percepção das divergências e na busca de uma visão convergente, mesmo que provisória e sujeita a novas contraposições.

No âmbito das ciências, a argumentação configura-se como uma forma de comunicar conhecimentos e ideias. Pode-se afirmar que a linguagem científica é, por natureza, uma linguagem argumentativa (KELLY, 2008; DRIVER; NEWTON; OSBORNE, 2000; DUSCHL; OSBORNE, 2002; KUHN, 1993). Mais ainda, considerando a argumentação como forma básica de pensamento, elaestaria vinculada aos processos de análise de problemas, dados, anomalias e conflitos, sustentados em paradigmas vigentes; em que, ao mesmo tempo, não é desconsiderada a possibilidade de novas formas de conceber fenômenos e a própria realidade que, por ora, permite uma dada interpretação. 
Assumindo os pressupostos destacados, em sala de aula, a argumentação estará em processo em distintos e diversos momentos, sobretudo na apresentação de uma nova perspectiva para conhecimentos e concepções que já existam acerca de um tema. As interações discursivas são promotoras do processo argumentativo, mas, ao mesmo tempo, fomentam as argumentações e colaboram para que sejam mais extensas e ricas em dimensões em análise. Desse modo, promover interações discursivas contribui diretamente para o desenvolvimento do pensamento e, consequentemente, para o desenvolvimento intelectual.

Em aulas de ciências é bastante comum adotar a argumentação no debate de pontos de vista distintos, colocando opiniões pessoais em confronto. Mas a apropriação da argumentação como estratégia de ensino vai além: a avaliação de problemas, os processos engendrados para sua resolução e a comunicação de ideias resultam em um trabalho argumentativo de envolvimento com a linguagem científica.

Entendemos, por isso, que, em aulas de ciências, a argumentação deflagra a oportunidade conferida aos estudantes para a participação nos processos de construção de entendimento, pois, via de regra, se mantém e se sustenta pelas interações discursivas ocorridas ao longo de uma aula. Sob esse ponto de vista, como já sugere Leitão (2011), a argumentação no contexto do ensino evidencia tanto aspectos vinculados ao raciocínio prático, quanto ao raciocínio teórico, aproximando alunos não apenas de conceitos, leis e teorias das ciências, mas também de processos e características da construção do conhecimento.

Essa perspectiva da argumentação coloca em evidência aspectos epistêmicos que superam o caráter linguístico e oferecem respaldo para que características próprias de uma área de conhecimento possam se fazer presentes. Para nosso caso, nas ciências da natureza, a construção de argumentos deflagra a busca por entendimento, validação e aceitação de proposições e processos de investigação em que justificativas e condições de contorno e de refutação precisam ser explicitadas.

Muito tem sido estudado em situações de ensino sobre as práticas e os movimentos epistêmicos que circundam a argumentação em aulas de ciências (LIDAR; LUNDQVIST; ÖSTMAN, 2005; SILVA, 2009; JIMÉNEZALEIXANDRE; BUGALLO RODRIGUEZ; DUSCHL, 2000; entre outros). A análise e os estudos que permitem classificar esses movimentos e essas práticas destacam aspectos das interações discursivas que são estabelecidas em sala de aula. Há, portanto, um claro viés didático fundamentando os processos argumentativos nas situações de ensino.

Mas em que consiste a argumentação em sala de aula? De que modo a possibilidade criada para quea argumentação ocorra em situações de ensino envolve o aprendizado de aspectos epistemológicos? Em outras palavras, o que há de ciência na ciência que é ensinada em sala de aula? 


\section{INVESTIGAÇÃO E ARGUMENTAC̣ÃO: PONTOS CULTURAIS DAS CIÊNCIAS E DE SEU ENSINO}

A atividade investigativa do cientista é ampla e complexa. Não se manifesta privilegiadamente por meio de uma estratégia específica, podendo estar associada a testes empíricos, experimentos de pensamento, análise e avaliação de dados e toda uma gama extensa de modos congregados. A argumentação científica, de modo semelhante, tambémpode se manifestar em distintas formas e em distintos momentos da produção e proposição de um conhecimento. Utilizando de estratégias para a persuasão ou a superação de conflito, a linguagem argumentativa tem o intuito central de delimitar o contexto de validade de uma afirmação, explicitando condições de contorno e condições de exceção associadas ao fato em alegação.

Tanto a investigação quanto a argumentação compõem aspectos do fazer científico e, por isso, correspondem a elementos da cultura científica.

Ao mesmo tempo, investigação e argumentação têm sido utilizadas como formas de tratar assuntos científicos em sala de aula. Explicitam-se não apenas como metodologias ou abordagens educativas, ocupando o papel de colocar em evidência aspectos culturais do fazer científico. Podem demarcar de modo mais claro o que é próprio da disciplina escolar relacionado às "ciências da natureza". Assim, correspondem a elementos da cultura escolar.

Em sala de aula, essa investigação e essa argumentação não são idênticas à prática realizada por aquele que faz ciência, mas, quando utilizadas com finalidade didática, podem permitir o desenvolvimento de entendimento sobre o que sejam as ciências, ao mesmo tempo em que são meios pelos quais conceitos, noções e modelos científicos são discutidos com os estudantes.

Izquierdo e Adúriz-Bravo (2003) propõem um olhar para a atividade que acontece em sala de aula de ciências identificando-a como uma "atividade científica escolar" em que os estudantes constroem modelos teóricos escolares que permitem a compreensão dos fenômenos naturais, a intervenção sobre eles e o estabelecimento de opiniões e juízos sobre processos e resultados.Essa concepção permite caracterizar a atividade escolar como uma tarefa híbrida (VIDAL, 2009; SCARPA, 2009) considerando a cultura escolar.

Tomada essa perspectiva, a prática de ofício proveniente da atividade científica escolar, ainda que possa se assemelhar ao processo de construção de conhecimento nas ciências, não representa integralmente a prática científica desenvolvida em laboratórios e centros de pesquisa. Para Gómez e Adúriz-Bravo (2007), a prática de ofício das atividades científicas escolares visa desenvolver o pensamento dos estudantes sobre os fenômenos do mundo natural, a partir da construção de "modelos teóricos escolares, apoiados nas práticas de observação e experimentação, na construção argumentada e compartilhada de evidências e na reformulação coletiva das ideias" (GÓMEZ; ADÚRIZ-BRAVO, 2007, p. 226, tradução nossa). 


\section{PODE-SE FALAR EM UMA CULTURA HÍBRIDA NA AULA DE CIÊNCIAS?}

A ideia de hibridismo é apresentada por Vidal (2009) como a mestiçagem de práticas que circundam ações em uma dada cultura podendo haver incorporação de práticas de uma cultura para concretização de afazeres em outra. Desse modo, seria possível conceber a integração e a compreensão de aspectos culturais de modo menos estranho e mais reconfortante pela identificação de similaridades.

Em sua tese de doutorado, Scarpa (2009) apresenta e discute a ideia de que a cultura escolar medeia o acesso e os processos de interação dos indivíduos com a cultura científica. A autora ainda propõe discussões sobre práticas híbridas avaliando a construção de argumentos pelos alunos em aulas de Biologia cujo tema tratado é a genética.

Partindo desses pressupostos, e considerando toda a ampla discussão já realizada acerca do Ensino de Ciências, reforçamos a ideia de hibridismo entre culturas, já apontada por autores como Vidal (2009), Scarpa (2009) e Gómez e Adúriz-Bravo (2007). No caso a que se refere este nosso trabalho, a hibridização estaria na relação entre cultura escolar e cultura científica e surgiria como uma marca para ações que visam ao desenvolvimentoda Alfabetização Científica entre os estudantes. Esse hibridismo entre cultura escolar e cultura científica caracterizar-se-ia tanto pelas relações encontradas e estabelecidas dentro da escola, como pelo compartilhamento e pela congregação de características que compõem cultura escolar e cultura científica.

Não se trata de pensar em desenvolver a cultura científica entre os estudantes, que se encontram em uma cultura escolar. Trata-se de conceber uma cultura científica escolar que influenciaria a constituição de normas e de práticas em sala de aula que atendessem não apenas a regras que vertem e regem as situações didáticas, mas um conjunto de normas e práticas escolares próprias e adequadas às aulas de ciências da natureza explicitando esse hibridismo.

Assim concebida, a sala de aula das ciências da natureza carregaria consigo elementos do fazer científico incorporados aos elementos que compõem o fazer didático. Isso leva-nos, uma vez mais, a refletir sobre as práticas investigativas e argumentativas colocadas em sala de aula pelo professor.

Conforme já tratamos, tanto o ensino por investigação quanto a argumentação em sala de aula trabalham com a necessidade de um problema que leve os estudantes ao engajamento com formas de resolver essa situação conflitante. Ao mesmo tempo, a resolução de problemas é identificada como tarefa vinculada às ciências e pode ser descrita como uma prática de ofício das ciências (GÓMEZ; ADÚRIZ-BRAVO, 2007). Envolve a resolução de problemas, ações como, por exemplo, a delimitação por condições de contorno, o controle de variáveis, o trabalho com hipóteses, em sua concepção e teste, a análise de dados e resultados, o confronto de informações, a busca por explicações, o estabelecimento de validação e os processos de generalização.

O ensino por investigação, pensado como abordagem didática, ressalta o papel do professor em colocar tais práticas em desenvolvimento. Ciente e 
conhecedor da disciplina que ministra e de questões epistemológicas que a fundamentam como área de conhecimento, é possível que o professor dê destaque aos detalhes epistêmicos e conceituais que circundam o tema que será trabalhado. Podemos identificar o professor como a autoridade social e a autoridade epistêmica (BERLAND; HAMMER, 2012) que, em aula, realiza perguntas e dispõe materiais e informações para que sejam analisados pelos alunos em uma perspectiva antes não avaliada. Ele é, desse modo, o responsável para explicitar o problema, que incita a investigação, e tornar possível a dialética que caracteriza a argumentação.

\section{UMA TENTATIVA DE CONCLUSÃO}

Ao longo do texto, algumas perguntas foram apresentadas. Ainda que linhas possam ter sido traçadas para respondê-las em seu diálogo como nosso artigo, gostaríamos de arriscar algumas considerações, valendo-nos da percepção da sala de aula de ciências da natureza como um espaço escolar e da concepção da escola como local de encontro de culturas. Seguiremos a ordem em que elas apareceram no texto:

1) Como colocar em implementação práticas em sala de aula que permitam que os alunos desenvolvam atitude crítica frente a temas científicos que afligem a sociedade?

Do modo como aparece nas salas de aulas da grande maioria das escolas brasileiras, refletindo aspectos ligados à concepção de ensino e sobre o currículo escolar dos docentes, a disciplina escolar de ciências da natureza pouco pode contribuir para o desenvolvimento dessa atitude crítica. Contudo, como corpo de conhecimento da humanidade que faz uso constante de análises críticas e de avaliações criteriosas, lógicas e, na medida do possível, objetivas sobre processos e situações do mundo natural, conhecer sobre as ciências da natureza pode contribuir para que os estudantes desenvolvam não apenas entendimento sobre os conceitos, mas também, e sobretudo, habilidades cognitivas para a investigação de problemas que surjam em seu entorno.

Nesse sentido, a ideia dos Eixos Estruturantes da Alfabetização Científica podenos auxiliar a planejar aulas que tragam para as situações de ensino uma abordagem mais geral e coesa das ciências. Isso porque esses três eixos exploram aspectos complementares para a aprendizagem e a percepção dos conhecimentos de ciências e sobre ciências. Ao mesmo tempo, considerando questões vinculadas a aspectos do fazer científico (abordados de modo mais claro no segundo desses eixos estruturantes), o ensino por investigação e a argumentação em sala de aula podem transparecer, uma vez que, privilegiadamente, permitem a abordagem de características do trabalho científico ao longo de seu desenvolvimento.

É importante ainda considerar que o ensino por investigação e a argumentação em sala de aula permitem romper com uma cultura escolar que se pauta, hegemonicamente, em práticas didáticas sem contextualização com o 
que é próprio do campo de conhecimento da disciplina. Em outras palavras, as práticas didáticas podem estar apenas ligadas a aspectos da cultura escolar, não permitindo o contato com aspectos da cultura científica ou mesmo o conhecimento de que ela existe.

Uma expectativa que surge dessas ideias é a possibilidade de que o gosto pelas ciências seja nutrido entre os estudantes ao compreenderem que as ciências são construções humanas, pautadas em crises, desafios, inquietações, podendo trazer inovações e mudanças para nossas vidas.

2) Qual o papel dos estudantes no ensino por investigação? Qual o papel do ensino por investigação na formação dos alunos?

O ensino por investigação, na perspectiva de uma abordagem didática, tal qual temos proposto, caracteriza-se por ser uma atividade colocada em prática pelo professor. Contudo, ela apenas se concretiza efetivamente pelas interações ocorridas entre professor, alunos, materiais e informações. Assim, o papel dos estudantes no ensino por investigação é crucial: o engajamento dos estudantes com as propostas trazidas pelo professor pode transformar uma tarefa burocrática em uma tarefa que gera aprendizado sobre conceitos e sobre ciências.

Entendemos que, a partir da investigação de situações-problema em sala de aula, os alunos têm oportunidade para desenvolver liberdade e autonomia intelectuais. Nesse processo, não apenas conhecimentos curriculares podem ser trabalhados, mas também aspectos ligados ao trabalho conjunto como, por exemplo, questões morais e éticas.

Ao mesmo tempo, ao promover condições para que os estudantes trabalhem ativa e conjuntamente na resolução de um problema, novas perguntas vão se construindo e se transformando em novas avaliações. Esse processo deflagra o estabelecimento de argumentação quando permite e solicita que haja debate de ideias explicitadas, oralmente ou graficamente, em tarefas escolares.

Considerando esse modo de propor atividades nas aulas de ciências, entendemos que os alunos se encontram no desenvolvimento da Alfabetização Científica, uma vez que atitudes de caráter crítico, social, racional e objetivo podem ser postas em prática juntamente e auxiliando a aprendizagem de conceitos das ciências.

Trata-se, portanto, de uma maneira de trabalhar temas e conteúdos das ciências da natureza colocando em destaque características que marcam o próprio fazer científico e, desse modo, podem congregar tanto aspectos da cultura escolar quanto da cultura científica.

3) Em que consiste a argumentação em sala de aula? De que modo a possibilidade criada para que a argumentação ocorra em situações de ensino envolve o aprendizado de aspectos epistemológicos? Em outras palavras, o que há de ciência na ciência que é ensinada em sala de aula?

O desenvolvimento da argumentação em sala de ciências já configura-se em uma abordagem de ensino que extravasa a simples apresentação de conteúdos de uma disciplina permitindo também o enfoque mais amplo e sistêmico de aspectos sobre a área de conhecimento. Assim, entendemos que, ao colocar a 
argumentação em prática, o professor traz a possibilidade de desenvolvimento de autoridade epistêmica entre os estudantes.

Mais uma vez é importante lembrar que a argumentação que tratamos é a argumentação em aulas de ciências e, por isso, engloba mais do que apenas características linguísticas de uma forma de enunciar ideias, sendo um processo de avaliação de enunciados, análise de possibilidades, refinamento de explicações e justificativas. Todas essas características que se assemelham a práticas próprias da cultura científica escolar.

Com base em todos esses apontamentos, entendemos que o ensino de ciências da natureza cujo objetivo maior seja a Alfabetização Científica precisa considerar perspectivas culturais da escola e das ciências, engendrando ações que respeitam e conciliam normas e práticas de ambas as culturas, mas que, ao mesmo tempo, percebe a importância de o Ensino de Ciências (ou o de qualquer outra disciplina escolar) ser trabalhado na perspectiva de Ensino de Ciências. Não se trata, pois, de pautar como objetivo a formação de cientistas; assim como não deve ser almejada a formação de estudantes que saibam usar os conhecimentos aprendidos tão somente em práticas circunscritas no âmbito escolar. $\mathrm{O}$ uso da abordagem didática do ensino por investigação parece-nos muito profícuo para o estabelecimento dessa cultura híbrida, a cultura científica escolar, permitindo que a argumentação, em sua forma e estrutura correspondente ao trabalho científico, faça-se presente e explicite o desenvolvimento dos estudantes para atuação e pertencimento à sociedade em que vivem, conhecendo e reconhecendo seus problemas e ajudando a enfrentá-los.

\section{AGRADECIMENTO}

Agradeço à Ana Paula Solino e ao Arthur Ferraz por todas as discussões que aqui se refletem.

\section{NOTA}

${ }^{1}$ LaPEF - Laboratório de Pesquisa e Ensino de Física da Faculdade de Educação da Universidade de São Paulo - Feusp.

\section{REFERÊNCIAS}

BARRELO JÚNIOR, N. Argumentação no discurso oral e escrito de alunos do ensino médio em uma sequência didática de física moderna. Dissertação - Faculdade de Educação da USP, São Paulo, 2010.

BERLAND, L.K.; HAMMER, D. Framing for scientific argumentation, Journal of Research in Science Teaching, 49 (1), 68-94, 2012. 
BYBEE, R.W.; DEBOER, G.E. Research on Goals for the Science Curriculum. In: GABEL, D. L. (ed.). Handbook of Research in Science Teacbing and Learning, New York:McMillan, 1994.

CAPECCHI, M. C. V. M. Aspectos da Cultura Científica em Atividades de Experimentaçãonas Aulas de Física, Tese de Doutorado - FE-USP, São Paulo, 2004.

CAPECCHI, M. C. V. M.; CARVALHO, A. M. P. Argumentação em uma Aula de ConhecimentoFísico com Crianças na Faixa de Oito a Dez Anos. Investigaçōes em Ensino de Ciências, v. 5, n. 2, p. 171-189, 2000.

CARVALHO, A. M. P.; SASSERON, L. H. Sequências de Ensino Investigativas - SEI: o que osalunos aprendem? In: TAUCHEN, G.; SILVA, J. A. da. (Org.). Educação em Ciências: epistemologias, princípios e ações educativas. Curitiba: CRV, 2012.

CARVALHO, A. M. P. Ensino e aprendizagem de ciências: referenciais teóricos e dadosempíricos das sequências de ensino investigativas.In: LONGHINI, M.D. O uno e o diverso naeducação. Uberlândia: EdUFU, 2011.

. O ensino de Ciências e a proposição de sequências de ensino investigativas. In: CARVALHO, A. M. P. (Org.). Ensino de Ciências por investigação: condiçõespara implementação em sala de aula. São Paulo: Cengage Learning, 2013.

CERTEAU, M. A invenção do cotidiano: 1. ed. Artes de fazer. Petrópolis: Vozes, 1994.

DRIVER, R., NEWTON, P.; OSBORNE, J. Establishing the norms of scientific argumentation inclassrooms. Science Education, 84 (3), p. 287-312, 2000.

DUSCHL, R. A.; OSBORNE, J. Supporting and Promoting Argumentation Discourse in ScienceEducation, Studies in Science Education, 38, p. 39-72, 2002.

EAGLETON, T. A ideia de cultura. São Paulo: Unesp, 2005.

ELIOT, T. S. Notas para uma definição de cultura. São Paulo: Perspectiva, 1988.

FERRAZ, A. T.; SASSERON, L. H. Ações do professor para promover argumentação em aulasinvestigativas. XIV EPEF - Encontro de Pesquisa em Ensino deFísica, Maresias, 2012.

FOUREZ, G. Alphabétisation Scientifique et Technique - Essai sur les finalités de l'enseignement des sciences. Bruxelas: DeBoeck-Wesmael, 1994.

GÓMEZ, A.; ADÚRIZ-BRAVO, A. La actividade científica escolar: Una actividade situada. Revista Configuraciones Formativas II: Formación e Praxis. México: Universidad de Guanajuato, 2007. p. 219-236.

GRANDY, R. E; DUSCHL, R. A. Reconsidering the character and role of inquiry in schoolscience: Analysis of a conference. Science and Education, 16, p. 141-166, 2007.

HURD, P. D. Scientific Literacy: New Minds for a Changing World, Science Education, 82(3), p. 407416, 1998.

IZQUIERDO, M.; ADÚRIZ-BRAVO, A. Epistemological foundations of school Science, Science \& Education, 12 (1), p. 27-43, 2003.

JIMÉNEZ-ALEIXANDRE, M. P.; BUGALLO RODRÍGUEZ, A.; DUSCHL, R. A. Doing the Lesson orDoing Science: Argument in High School Genetics. Science Education, v. 84, p. 757-792, 2000.

JULIA, D. A cultura escolar como objeto histórico. Revista Brasileira de História daEducação, n. 1, p. 9-44, 2001.

KELLY, G. J. Inquiry, activity and epistemicpractice. In: DUSCHL, R. A.; GRANDY, R. E. Teacbing Scientific Inquiry: recommendations for research and implementation. Rotterdam, Taipei, Sense Publishers, 2008.

KUHN, D. Science as argument: Implications for teaching and learning scientific thinking, Science Education, v. 77, n. 3, p. 319-337, 1993.

LATOUR, B; WOOLGAR, S. A Vida de Laboratório: A produção dos fatos científicos. RelumeDalmará, 1997.

LEITÃO, S. O lugar da argumentação na construção do conhecimento. In: LEITÃO, S.; DAMIANOVIC, M. C. (Org.), Argumentação na escola: O conhecimento em construção. Campinas: Pontes Editores, 2011.

LIDAR, M; LUNDQVIST, E.; ÖSTMAN, L. Teaching and learning in the science classroom: theinterplay between teachers' epistemological moves and students' practical epistemology. Science Education. 90: 148-163, 2005. 
LOCATELLI, R. J. Uma Análise do Raciocinio Utilizado pelos Alunos ao Resolverem os Problemas Propostos nas Atividades de Conbecimento Físico, Dissertação - Instituto de Física e Faculdade de Educação da USP, São Paulo, 2006.

MACHADO, V. F.; SASSERON, L. H. As perguntas em aulas investigativas de ciências: aconstrução teórica de categorias. Revista Brasileira de Pesquisa em Educação em Ciências, v. 12, p. 29-44, 2012.

MACHADO, V. F. A importância da pergunta na promoção da Alfabetização Científica dosalunos em aulas investigativas de Física, dissertação apresentada ao Instituto de Física e à Faculdade de Educação da USP, 2012.

SASSERON, L. H.; CARVALHO, A. M. P. Almejando a alfabetização científica no ensino fundamental: a proposição e a procura de indicadores do processo. Investigações em Ensino de Ciências, v. 13, n. 3, p. 333-352, 2008.

SASSERON, L. H.; CARVALHO, A. M. P. Construindo argumentação na sala de aula: a presença dociclo argumentativo, os indicadores de Alfabetização Científica e o padrão de Toulmin. Ciência e Educação, v. 17, p. 97-114, 2011.

SASSERON, L. H. Alfabetização Científica no ensino Fundamental: Estrutura eIndicadores deste processo em sala de aula.Tese - Faculdade de Educação da USP, São Paulo, 2008.

SCARPA, D. L. Cultura escolar e cultura cientifica: aproximações, distanciamentos ehibridações por meio da análise de argumentos no ensino de biologia e na Biologia.Tese - Faculdade de Educação da USP, São Paulo, 2009.

SILVA, A. C. T. Estratégias enunciativas em salas de aula de química: contrastandoprofessores de estilos diferentes. Tese - Faculdade de Educação da UFMG, Belo Horizonte, 2009.

VIDAL, D. G. No interior da sala de aula: ensaio sobre cultura e prática escolares. Currículo sem Fronteiras, v. 9, n. 1, p. 25-41, 2009.

VIÑAO FRAGO, A.; ESCOLANO, A. Currículo, espaço e subjetividade: a arquitetura comoprograma. Rio de Janeiro: DP\&A, 1998.

WHITE, L. A.; DILLINGHAM, B. O conceito de cultura. Rio de Janeiro: Contraponto, 2009. 